Check for updates

Cite this: J. Mater. Chem. B, 2020 8, 10182

Received 15th July 2020,

Accepted 2nd October 2020

DOI: 10.1039/d0tb01748e

rsc.li/materials-b

\section{MOF based flexible, low-cost chemiresistive device as a respiration sensor for sleep apnea diagnosis $\dagger$}

\author{
T. Leelasree, ${ }^{a}$ Venkatarao Selamneni, (DD b ${ }^{\mathrm{b}}$ T. Akshaya, ${ }^{\mathrm{b}}$ Parikshit Sahatiya (iD ${ }^{\mathrm{b}}$ and \\ Himanshu Aggarwal (iD *a
}

\begin{abstract}
The monitoring of respiratory disorders requires breath sensors that are fast, robust, and convenient to use and can function under real time conditions. A MOF based flexible sensor is reported for the first time for breath sensing applications. The properties of a highly porous HKUST-1 MOF and a conducting $\mathrm{MoS}_{2}$ material have been combined to fabricate an electronic sensor on a flexible paper support for studying sleep apnea problems. Extensive breath sensing experiments have been performed and interestingly the fabricated sensor is efficient in detecting various kinds of breaths such as deep, fast, slow and hydrated breath. The MOF breath sensor shows a fast response time of just $\sim 0.38 \mathrm{~s}$ and excellent stability with no decline in its performance even after a month. A plausible mechanism has been proposed and a smartphone based prototype has been prepared to demonstrate the real time applications of the hybrid device. This work demonstrates great potential for the application of MOFs in healthcare with a special focus on breath sensing and sleep apnea diagnosis.
\end{abstract}

\section{Introduction}

Metal-organic frameworks (MOFs), hybrid materials consisting of organic-inorganic building units, have emerged as a popular class of porous materials which have shown widespread applications in the areas of gas storage, separation, drug delivery, catalysis, etc. $^{1-5}$ Owing to their high porosity, stability and ease of fine tuning, MOFs are a desirable choice for chemists for designing materials for challenging applications. ${ }^{6,7}$ The easy tunability and uniform pore size of MOFs provide an edge over their counterparts such as zeolites and silica. Besides gas sorption and storage, MOFs have also been used for various types of sensing applications, such as sensing of gases, volatile-organic compounds (VOCs), biomolecules, amines and explosives. $^{8-13}$ In most of the cases, sensing is demonstrated with the help of well-known techniques such as UV-Vis spectroscopy, fluorescence and IR spectroscopy. ${ }^{14,15}$ These methods do provide important information on the sensing behaviour of an

\footnotetext{
${ }^{a}$ Department of Chemistry, Birla Institute of Technology and Science, Hyderabad Campus, Hyderabad 500078,

IndiaE-mail: himanshu.aggarwal@hyderabad.bits-pilani.ac.in

${ }^{b}$ Department of Electrical and Electronics Engineering, Birla Institute of Technology and Science Pilani, Hyderabad Campus, Hyderabad 500078, India

$\dagger$ Electronic supplementary information (ESI) available: Materials and physical measurements, experimental section, additional structural figures, PXRD patterns, TGA curves, XPS, and breath sensing experimental details. See DOI: 10.1039/d0tb01748e
}

MOF material towards different analytes. However, attempts to fabricate MOF materials into fully electronic devices for real time applications have rarely been made. ${ }^{16,17}$ The fabrication of the materials into electronic devices is an important and extremely practical approach from an application point of view since it shows the prospects of using the materials under real time conditions.

The role of MOFs in water capture and storage has lately gained a lot of attention. ${ }^{18}$ In 2014, Yaghi and co-workers showed how MOFs could be a potential candidate for capturing water from air in the desert areas that suffer from high water scarcity. ${ }^{19,20}$ Since then there have been various reports on using MOFs for water capture, dehumidification and humidity sensing. ${ }^{21,22}$ Recently, the Eddaoudi group reported Cr-soc-MOFs for indoor humidity control with exceptional water uptake capacity. ${ }^{23}$ Due to their excellent water capturing capabilities, it could be interesting to employ MOFs for studying human breath patterns which has not been done to date. The amount of water present in different types of breaths such as slow, fast, hydrated, and dehydrated breath is different and such changes could be monitored using an electronic device that can function at different humidity levels.

A recent surge in healthcare demands makes it imperative to design better materials for detection and cure of numerous common health related problems. ${ }^{24}$ MOFs, so far, have not been studied meticulously for the fabrication of sensing devices that may offer solutions to challenges pertaining to the healthcare 
sector. One of the common health problems that needs to be taken care of is Obstructive Sleep Apnea (OSA) which is severe sleep disorder with issues such as excessive day time sleeping, fatigue and cardiovascular diseases associated with it. ${ }^{25,26}$ OSA is caused by air blockage during sleep which reduces the blood flow to the brain. Approximately $2 \%$ of women and $4 \%$ of men are affected by OSA but more than $90 \%$ of the cases go undiagnosed. $^{27}$ This is due to the lack of handy techniques for diagnosis of OSA. Polysomnography is a common technique which needs bulky instruments and is also invasive and disturbs sleep, which results in inaccurate readings. ${ }^{28}$ Lately, there have been research on breath and flow sensors for diagnosis of OSA. ${ }^{29}$ However, most of the devices are contact based sensors which have strict positional requirements and hence do not serve the purpose of patient comfort. There are recent reports on non-contact breath sensors for various applications, ${ }^{30-32}$ but the signal to noise ratio of such sensors is low, which leads to inaccurate results. To achieve a high signal to noise ratio, the materials utilized for sensing should be highly sensitive to breath and should be able to provide a large signal output even for smaller quantities of input. For this, it is important to explore materials that have excellent water adsorption properties. MOFs are well known for their water adsorption capacities, ${ }^{33}$ and it will be fascinating to study them for real time breath sensing applications for healthcare monitoring.

However, a big challenge in the case of employing MOFs for the fabrication of electronic devices is their inherently poor conductivity. ${ }^{34}$ MOFs are generally not good conductors and therefore it becomes necessary to have an underlying conducting support that offers a viable route for electron transport for smooth functioning of the devices. In search of a conducting support, transition metal dichalcogenides (TMDs), which are a class of 2-dimensional materials that are atomically thin, have gained significant attention due to their intriguing electronic, chemical and mechanical properties. ${ }^{35,36}$ MOFs are well known for their adsorption properties that assist in capturing a greater amount of water molecules exhaled from breath and $\mathrm{MoS}_{2}$ acts as an active site for electron exchange and transport due to its excellent electron mobility. ${ }^{37-39}$ It would be very interesting to combine these two excellent classes of materials and utilize their individual properties for enhanced sensing behaviour towards breath sensing for obstructive sleep apnea applications.

\section{Results and discussion}

Here we report a HKUST-1 MOF/MoS 2 based hybrid flexible respiration sensor for sleep apnea diagnosis. HKUST-1 was synthesized by a solvothermal approach using a reported procedure (Scheme 1). ${ }^{40}$ The secondary building unit (SBU) of the HKUST-1 structure consists of a $\mathrm{Cu}$ paddlewheel where the $\mathrm{Cu}-\mathrm{Cu}$ dimers are coordinated to benzene tricarboxlyate linkers (BTC). The tricarboxylate linker acts as a 3-c node, whereas the $\mathrm{SBU}, \mathrm{Cu}_{2}\left(-\mathrm{CO}_{2}\right)_{4}$, acts as a 4 -c node. The underlying net is binodal with a $(3,4)$-coordinated tbo topology. The metal

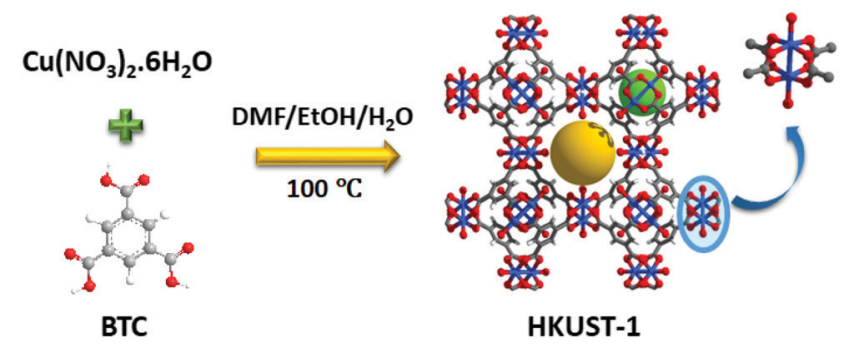

Scheme 1 Schematic illustration of HKUST-1 synthesis and its crystal structure.

clusters also contain coordinated water molecules that can render active metal sites upon complete activation (Scheme 1). The phase purity of the as-synthesized material was confirmed by comparing the powder X-ray diffraction (PXRD) patterns of the as-synthesized material with those of the reported structure (Fig. S1, ESI $\dagger$ ). HKUST- 1 has a pore diameter of about $9 \AA$ with a pore window size around $6 \AA^{41}$

Thermogravimetric analysis shows solvent loss till $150{ }^{\circ} \mathrm{C}$ and decomposition beyond $300{ }^{\circ} \mathrm{C}$ (Fig. S2, ESI $\dagger$ ). The BET surface area for the pristine and the ground samples was determined using nitrogen gas at $77 \mathrm{~K}$ (Fig. S3a and b, ESI $\dagger$ ). Prior to the adsorption experiment, the crystals were activated at $125{ }^{\circ} \mathrm{C}$ under dynamic vacuum. The framework shows a BET surface area of $1498 \mathrm{~m}^{2} \mathrm{~g}^{-1}$ with $0.665 \mathrm{~cm}^{3} \mathrm{~g}^{-1}$ pore volume (Fig. S3 and S4, ESI $\dagger$ ). The experimental pore diameter is around $8 \AA$ which is very close to the literature value. ${ }^{41}$ The water stability of the MOF sample was established before carrying out humidity experiments, by immersing the crystals in water for $24 \mathrm{~h}$ and the PXRD patterns were recorded before and after exposure to water. The MOF sample showed no deterioration in crystallinity and the PXRD patterns matched closely with those of the as-synthesized sample (Fig. 1).

$\mathrm{MoS}_{2}$ was grown directly on a cellulose paper substrate using a solution processed hydrothermal method as shown in Scheme 2. The direct growth of $\mathrm{MoS}_{2}$ on paper involves two steps: a seeding process followed by hydrothermal growth. Seed solution was prepared by properly mixing $\mathrm{Na}_{2} \mathrm{MoO}_{4} \cdot 2 \mathrm{H}_{2} \mathrm{O}$ $(10 \mathrm{mM})$ and $\mathrm{CH}_{4} \mathrm{~N}_{2} \mathrm{~S}(20 \mathrm{mM})$ in deionized (DI) water $(10 \mathrm{ml})$. A paper substrate of dimension $3 \mathrm{~cm} \times 3 \mathrm{~cm}$ was immersed in the seed solution for 40 minutes followed by drying at $70{ }^{\circ} \mathrm{C}$ for 15 minutes. Nutrient solution was prepared by mixing $\mathrm{Na}_{2} \mathrm{MoO}_{4}$. $2 \mathrm{H}_{2} \mathrm{O}(50 \mathrm{mM})$ and $\mathrm{CH}_{4} \mathrm{~N}_{2} \mathrm{~S}(100 \mathrm{mM})$ in $30 \mathrm{ml}$ of DI water.

The seed coated cellulose paper and the well dispersed nutrient solution were transferred to a Teflon lined stainless steel autoclave and kept in a hot air oven for 20 hours at $200{ }^{\circ} \mathrm{C}$. After that, the autoclave was allowed to cool down and the resultant $\mathrm{MoS}_{2}$ coated cellulose paper was annealed at $70{ }^{\circ} \mathrm{C}$ for 20 minutes. In order to have uniform coating, the MOF crystals were first gently ground with a mortar and pestle in the presence of ethanol and then the ground sample was dropcast on the $\mathrm{MoS}_{2}$ /cellulose paper (Scheme 2). The PXRD patterns of the dropcast HKUST-1 sample on $\mathrm{MoS}_{2}$ and the as-synthesized crystals were compared to confirm the integrity of the MOF sample after coating on the $\mathrm{MoS}_{2}$ support (Fig. 1). 

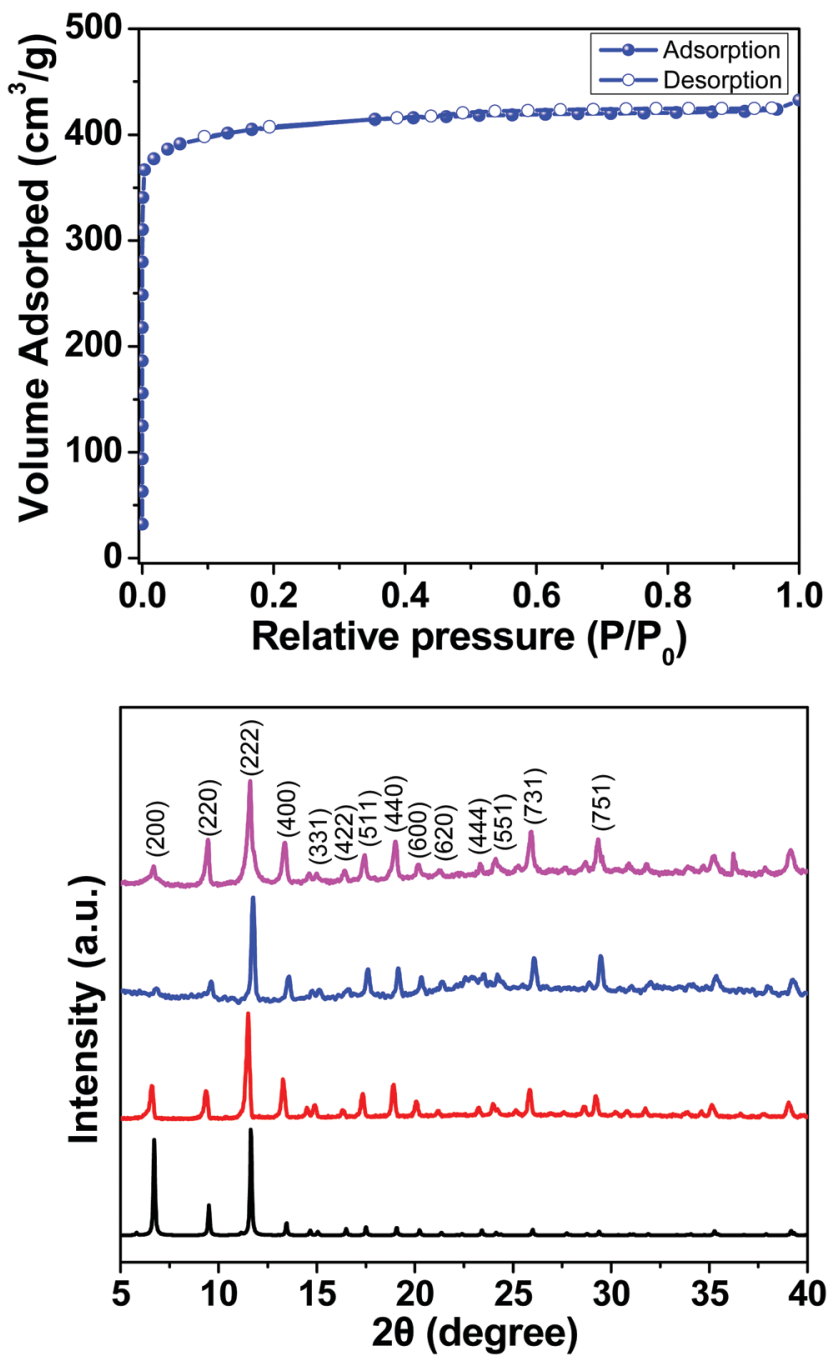

Fig. $1 \mathrm{~N}_{2}$ adsorption isotherm of HKUST-1 (top), and a comparison of the PXRD patterns of the HKUST-1 MOF sample under different conditions (bottom); calculated (black), as-synthesized HKUST-1 crystals (red), the HKUST-1 sample dropcast on MoS 2 (blue), and the HKUST-1 sample after exposure to water for $24 \mathrm{~h}$ (pink).

To study the morphology, FESEM analysis was carried out on the as-synthesized single crystals, ground sample, $\mathrm{MoS}_{2}$ on cellulose paper and ground MOF sample coated on $\mathrm{MoS}_{2}$ (Fig. $2 \mathrm{a}-\mathrm{c}$ and Fig. S5a-c, ESI $\dagger$ ). The size of the as-synthesized single crystals ranges from 10 to $30 \mu \mathrm{m}$ (Fig. 2a). The uniform coating of the MOF material on the support can be observed in Fig. 2c. EDX analyses were also carried out to ascertain the elemental composition of the HKUST-1 samples (Fig. S6, ESI $\dagger$ ). Fig. 2d shows the XPS survey spectra of the MOF coated on the $\mathrm{MoS}_{2}$ /paper, wherein the binding energy peaks confirm the presence of $\mathrm{Cu}, \mathrm{Mo}, \mathrm{S}, \mathrm{C}$ and $\mathrm{O}$ elements. Fig. 2e shows a high resolution XPS spectrum of $\mathrm{Cu} 2 \mathrm{p}$, wherein two characteristic peaks corresponding to $\mathrm{Cu} 2 \mathrm{p}_{3 / 2}$ and $\mathrm{Cu} 2 \mathrm{p}_{1 / 2}$ were observed at $934.8 \mathrm{eV}$ and $954.8 \mathrm{eV}$, respectively, suggesting that $\mathrm{Cu}$ exists as the $\mathrm{Cu}^{2+}$ oxidation state. ${ }^{42,43}$ A deconvoluted Mo 3d high resolution spectrum is shown in Fig. 2f; it contains two doublet peaks at $228.4 \mathrm{eV}$ and $231.7 \mathrm{eV}$, which signifies the presence of
$\mathrm{Mo}^{4+} 3 \mathrm{~d}_{5 / 2}$ and $\mathrm{Mo}^{4+} 3 \mathrm{~d}_{3 / 2}$, respectively. Two more peaks were observed at $225.5 \mathrm{eV}$ and $235.7 \mathrm{eV}$ corresponding to $\mathrm{S} 2 \mathrm{~s}$ and $\mathrm{Mo}^{6+} 3 \mathrm{~d}$, respectively, and the presence of the $\mathrm{Mo}^{6+}$ oxidation state can be attributed to the existence of a small amount of unreacted $\mathrm{MoO}_{4}{ }^{2-}$ during the synthesis of $\mathrm{MoS}_{2} \cdot{ }^{44}$ The high resolution spectrum of $\mathrm{S} 2 \mathrm{p}$, wherein two spin orbit coupling peaks of $\mathrm{S} 2 \mathrm{p}_{3 / 2}$ and $\mathrm{S} 2 \mathrm{p}_{1 / 2}$ are observed at $161.4 \mathrm{eV}$ and $162.5 \mathrm{eV}$ respectively, suggests the $\mathrm{S}^{2-}$ state of $\mathrm{S}$ as shown in Fig. S7 (ESI $\dagger$ ). ${ }^{45}$ Similarly, the binding energies for O1s and C1s have also been shown (Fig. S7, ESI $\dagger$ ).

Breath sensing experiments were conducted in a sequential manner, whereby the response of the MOF coated device was tested by keeping the device $4 \mathrm{~cm}$ away from the nose of an individual. Fig. 3 shows the temporal response of the fabricated device under normal breath (12 breaths per min) where a few seconds delay was given in between consecutive breaths under ambient conditions. Interestingly, during exhalation, an increase in the device current was observed and during inhalation the current decreased, which clearly shows that the fabricated device can be useful for detecting variations in breath. It should be noted that the current does not return to its initial value, which can be attributed to the slow rate of desorption/removal of water molecules. HKUST-1 is known to retain water even at $0 \%$ relative humidity under nitrogen stream and complete desorption takes place only after reactivation of the material. ${ }^{46}$ Also, achieving a stable baseline is not important in breath sensing, as the application demands counting of the number of breaths which corresponds to the number of current peaks. To further analyse the capability of the device, it is tested for breath patterns such as slow ( 6 breaths per min) and fast breath (17 breaths per min), wherein the frequency of the breath pattern is the key observation. Fig. 3 shows the temporal response of the fabricated sensor under a slow and fast breath pattern, respectively. Compared to a normal breath pattern, in a fast breath pattern, the frequency of the peaks increased by $\sim 42 \%$. Similarly, in the case of a slower breath pattern, the frequency decreased by $\sim 50 \%$. The temporal response of the fabricated device under a deep breath pattern ( 8 breaths per $\mathrm{min}$ ) is also shown in Fig. 3, and an $8-14 \%$ increment in the peak value of the sensor current was observed.

To check the repeatability of the experiments, the fabricated device was tested for iterative breath patterns, wherein the individual was asked to take 3 consecutive exhalations. The same experiment was repeated for 5 cycles with a suitable time gap in between each cycle for the sensor current to regain its initial value (Fig. S8, ESI $\dagger$ ). Further, the same experiment with three iterative breathing patterns was performed for $\sim 1000 \mathrm{~s}$ (Fig. S8, ESI $\dagger$ ) and a negligible change in the device performance was observed, which demonstrates the robustness and reliability of the fabricated sensor. This clearly shows that if the delay time between the two consecutive cycles is more than the desorption time, then the sensor current regains its initial current value. In addition, the fabricated device was tested at different hydration levels (Fig. S9, ESI $\dagger$ ). When the hydration levels of the breath are high, a higher amplitude of the device current upon breath exhalation was observed. Similarly, 


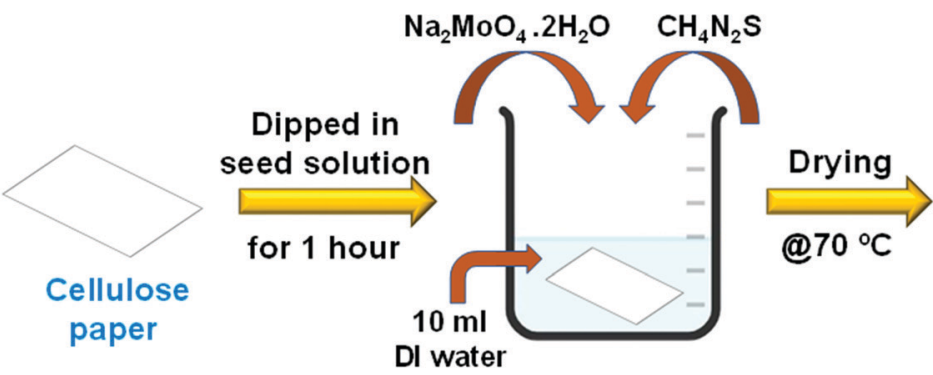

DI water

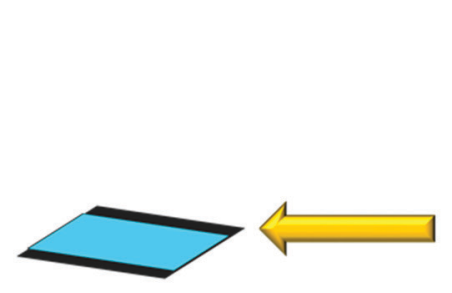

MOF-Mos 2 on paper substrate
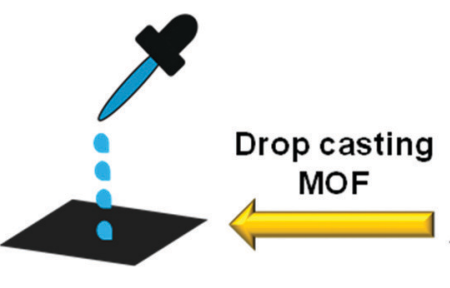

MoS $_{2}$ grown on Cellulose paper

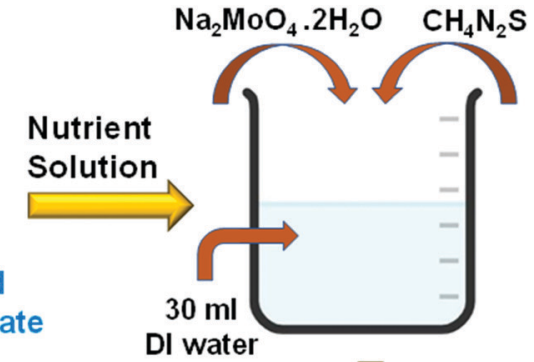

Transfer solution and substrate

Seed Coated paper substrate
Dl water

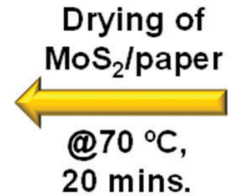

20 mins.

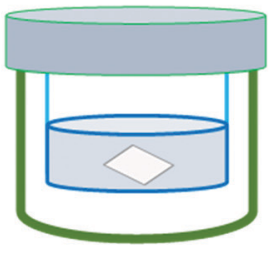

Hydrothermal for

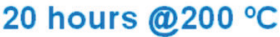

Scheme 2 Schematic illustration of growing $\mathrm{MoS}_{2}$ on a cellulose paper substrate and dropcasting of MOF powder on the MoS 2 support for device fabrication.
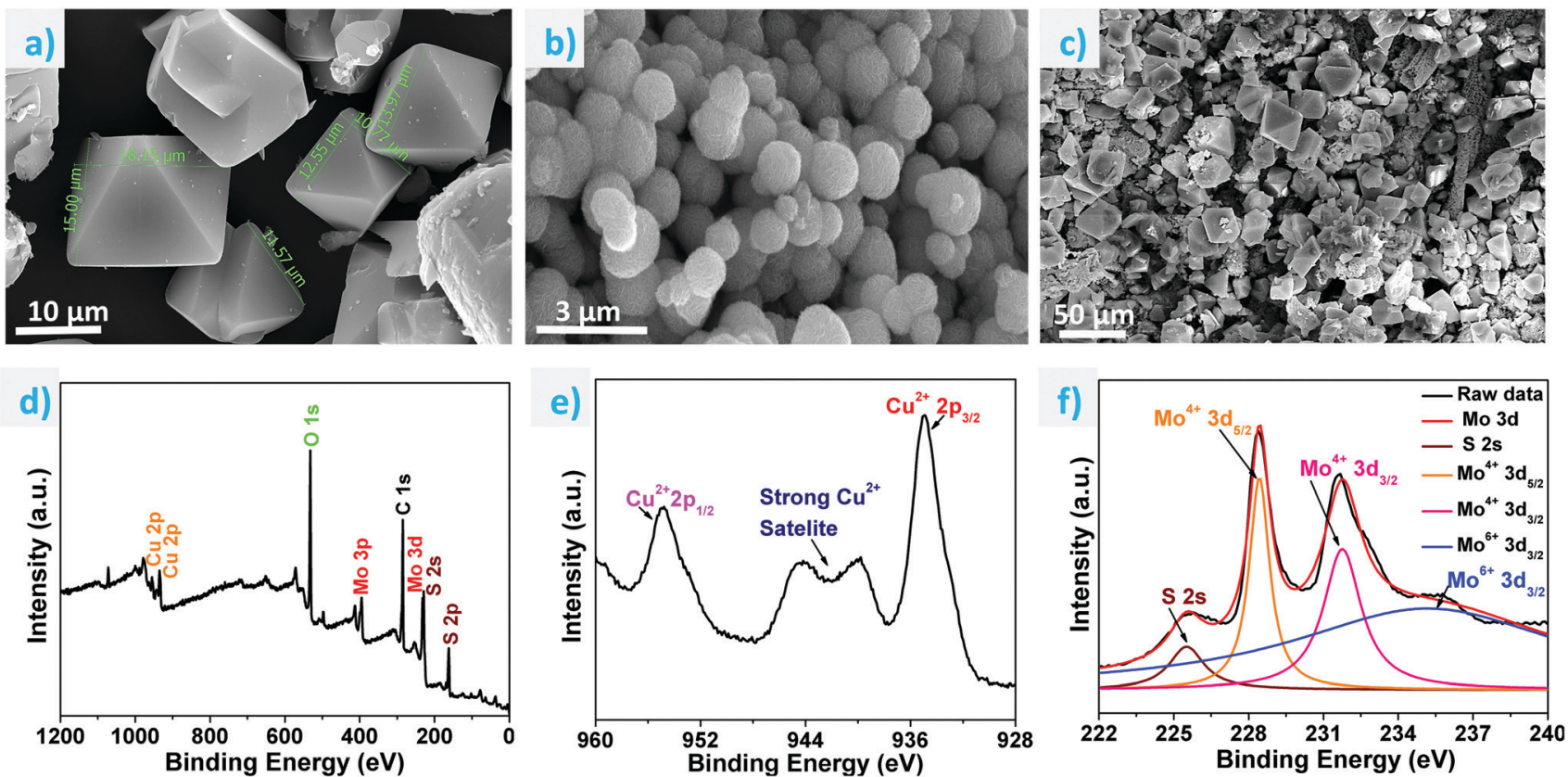

Fig. 2 SEM images of (a) HKUST-1 single crystals, (b) MoS 2 , and (c) HKUST-1 ground sample dropcast on the MoS 2 support, and the XPS data of the HKUST-1-MoS 2 sample; (d) full XPS spectrum; (e) Cu 2p XPS spectrum; and (f) Mo 3d, S 2s XPS spectrum.

an inverse experiment was also performed, wherein the individual was not allowed to drink water for 6 hours and then breath exhalation experiments were performed, and as observed, the amplitude of the device current was low when compared to the normal breath. The variation in the amplitude of the device current suggests that it could be potentially applied as a diagnostic tool for hydration monitoring.
Further to verify the long-term durability, the fabricated device was tested over a period of 4 weeks under ambient conditions, wherein readings were taken once in a week (Fig. S10, ESI $\dagger$ ). It is noteworthy that the HKUST-1-MoS 2 hybrid device showed excellent stability with no decline in its performance even after a month. Similar breath pattern experiments were performed for pristine $\mathrm{MoS}_{2}$, and temporal response graphs were 

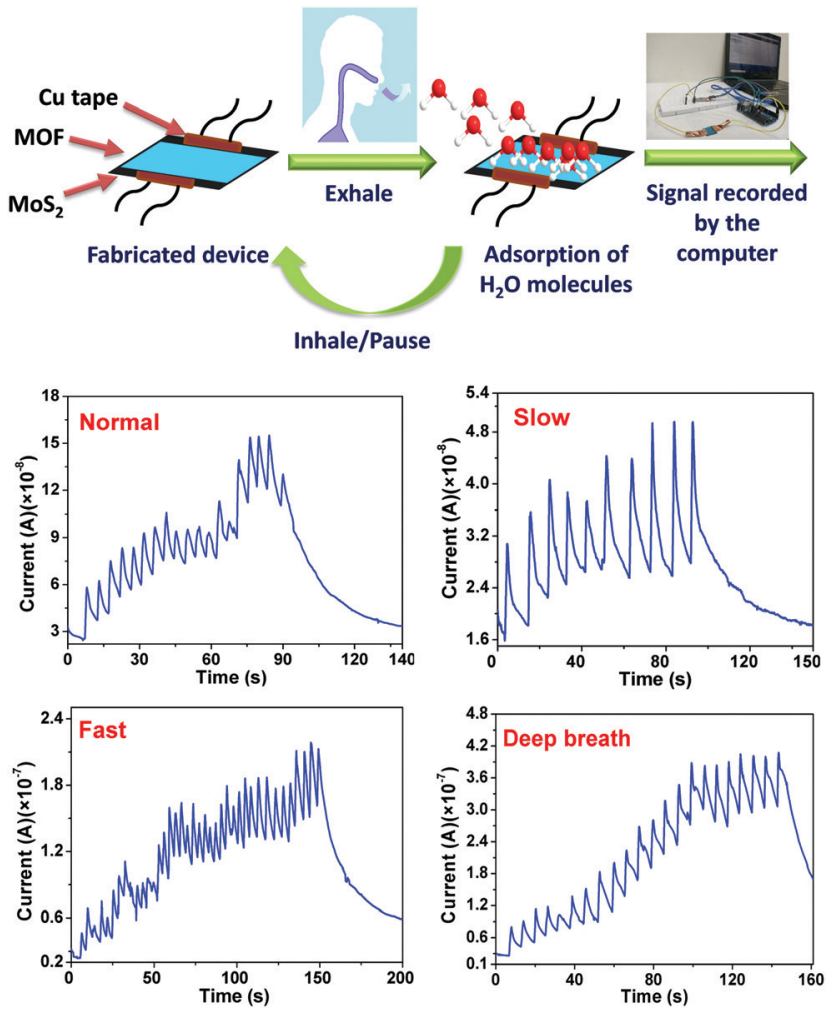

Fig. 3 (top) HKUST-1-MoS 2 fabricated sensor for breath sensing, and (bottom) breath sensing experiments showing variation in the current in response to different types of breaths: normal breath, slow breath, fast breath and deep breath.

recorded, (Fig. S11, ESI $\dagger$ ). It was observed that the performance of the HKUST-1- $\mathrm{MoS}_{2}$ hybrid device is superior to that of the pristine $\mathrm{MoS}_{2}$ due to better water adsorbing properties of the MOF material. Besides testing the long term stability of the device, we also calculated its response time. The response time is an important parameter that defines the efficiency of the device in terms of the time that it takes to reach the maximum value (current in this case) upon expiration. Interestingly, the response time for the HKUST-1-MoS ${ }_{2}$ device is only $\sim 0.38 \mathrm{~s}$, which shows that it is feasible for this device to work in sleep apnea diagnosis (Fig. S12, ESI $\dagger$ ).

The response time of the HKUST-1- $\mathrm{MoS}_{2}$ hybrid device has been compared with those of various benchmark materials reported in the literature that include metal oxides, polymers, zeolites, graphene oxides, etc. (Table S1, ESI $\dagger$ ). To the best of our knowledge, there are no reports available on MOF based breath sensors and the current work is the first study in this direction that realizes the potential of MOF materials for real time healthcare based applications. Moreover, the response time of our device is better than those of many other materials that have been reported for breath sensing. Additionally, the use of a cellulose paper based flexible support in the present case provides a much more economical alternative when compared to other support materials such as ceramics or silicon.

In order to gain deeper insights into the humidity sensing performance of the HKUST-1-MoS 2 hybrid device, we looked into the possible mechanism of water and charge transport through the MOF and $\mathrm{MoS}_{2}$ layers. Due to its large pore diameter, pore volume and open metal sites, HKUST-1 adsorbs a large amount of water molecules in a short span of time. As per the literature reports, the water loading can go up to $32 \mathrm{mmol} \mathrm{g}^{-1}$ for HKUST- $1 .{ }^{47}$ On the other hand, $\mathrm{MoS}_{2}$ is an excellent charge carrier which can enable rapid electron transport, thus ensuring a smooth response in current change with a change in humidity. The physical sensing mechanism can be attributed to the resistance modulation of $\mathrm{MoS}_{2}$ due to the adsorption of water molecules exhaled from breath. Hence, when the MOF/MoS 2 device is exposed to breath, the relative humidity increases in the vicinity of the device and the excellent water adsorbing capability of HKUST-1 leads to maximum amount of water molecules being captured and transported to $\mathrm{MoS}_{2}$. Moreover, the metal clusters in HKUST-1 have coordinated water molecules that are known to have sufficient acidic character, and therefore these water molecules lose protons much faster as compared to the uncoordinated water molecules. ${ }^{48}$ These acidic water molecules contribute protons to the water and ethanol molecules present in the pores which leads to an enhancement of conductivity (Fig. 4). Also, water molecules are electron donating species, and they donate electrons to n-type $\mathrm{MoS}_{2}$ which increases the majority of carrier concentration of $\mathrm{MoS}_{2}$, thereby increasing the current value. Further, as the water molecule gets adsorbed on $\mathrm{MoS}_{2}$, the energy band bends downwards which creates an easy path for the electrons to flow towards the metal.

Upon inhalation, a reverse process occurs. As soon as the inhalation process starts, the water molecules that were adsorbed on the surface of $\mathrm{MoS}_{2}$ now start to remove/desorb from the surface which creates an upward band bending, thereby allowing the fabricated device to start coming to its initial resistance. However, since HKUST-1 has a slow desorption rate, the device does not get enough time to reach its baseline (i.e. when all the water molecules are desorbed/ removed) resistance/current value and the current value once

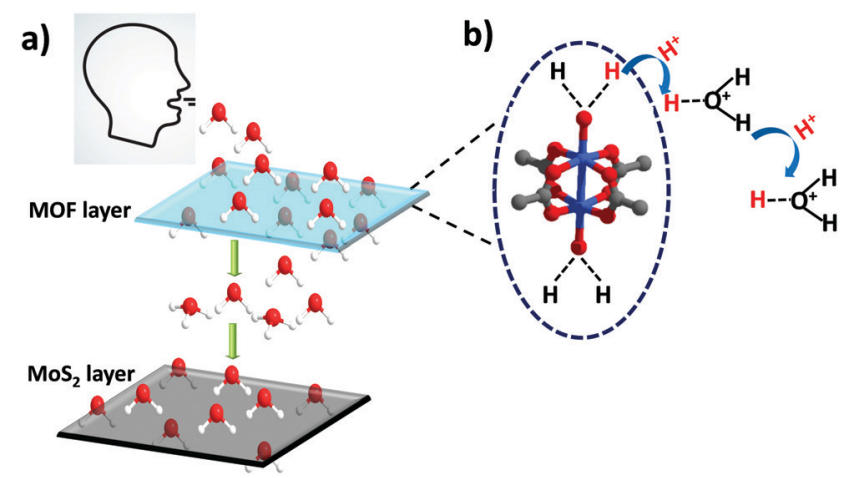

Fig. 4 Breath sensing mechanism in the HKUST-1-MoS 2 integrated device. (a) Adsorption and transfer of water molecules from the MOF to the $\mathrm{MoS}_{2}$ layer and (b) the mechanism of proton conduction in the MOF layer involving proton transfer from acidic water molecules coordinated to the metal cluster to the solvent molecules present in the channels. Only one cluster has been shown for clarity. 

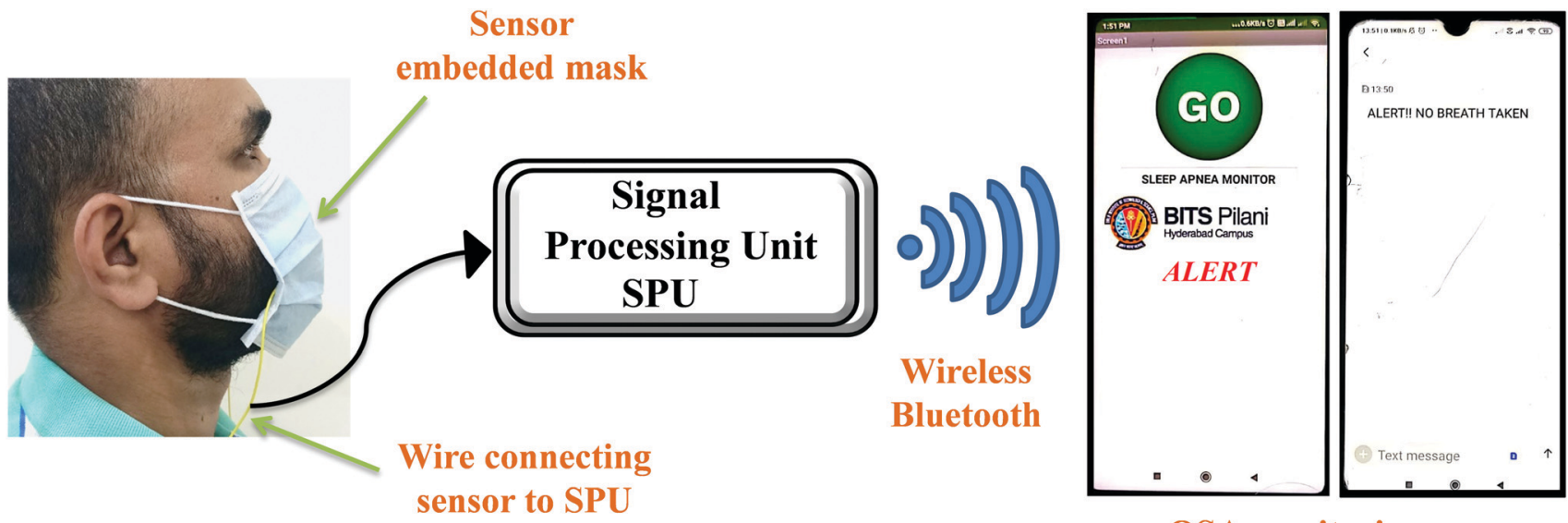

OSA monitoring app

Fig. 5 Schematic illustration of the face mask with the embedded HKUST-1-MoS 2 device showing real time operation using a smartphone device.

again increases with the next breath. Hence, the combination of HKUST- 1 and $\mathrm{MoS}_{2}$ provides a remarkable system that works in tandem for the smooth functioning of the device.

Furthermore, to demonstrate the real time application of the fabricated respiration sensor, a proof of concept prototype was developed, wherein the sensor was integrated onto a mask and the data were collected via a smartphone (Fig. 5, Fig. S13 and Video S1, ESI $\dagger$ ). For doing so, the fabricated device was integrated into an Arduino microcontroller which measures the data and then transfers it to the smartphone using Bluetooth wireless communication. The data received by the smartphone were analysed for the risk of a patient towards sleep apnea through a dedicated user-friendly Android application. The analysis was performed by observing the breath pattern and also by counting the number of breaths. Importantly, the device triggers an alarm whenever there is a risk of patient breath slowing down. Fig. 5 shows the real time fabricated device and its integration on the mask which is connected to Arduino and the smartphone. For sleep apnea diagnosis, it is important to continuously monitor the breath and not the amplitude of the breath. With variation in the distance, the amplitude of the signal may vary which does not affect the intended application.

A prototype face mask is prepared as shown in Fig. 5 to ascertain the appropriate working of the device under real time conditions. A simple resistive circuit was employed to measure the resistance of the sensor. For the transfer of sensor data, the Bluetooth Module (HC-05) was employed which utilized the serial port communication. To verify the reliability of the fabricated sensor and the effective communication between the controller and the smartphone, three different instances were tested: (1) normal breathing (no alert), (2) breathing stopped but again continued (abnormal - no alert), and (3) breathing stopped (abnormal - alert) (Fig. 5 and Fig. S14, ESI $\dagger$ ). Fig. 5 shows the snapshots of the Android applications for the transmission of the alert message to the doctor/nurse/ guardian when the patient missed a breath. The typical breath rate of a healthy adult is in the range of 10-20 times per minute. If the breath pattern is not in this specified range, it is considered as an abnormal breathing pattern. ${ }^{49,50}$ If the patient does not breathe for 20 seconds, then the alarm for breathing stopped would be triggered (Video S1, ESI $\dagger$ ). This would alert the doctor about the abnormal respiratory condition of the patient and thus help the doctor in saving the patient's life.

\section{Conclusions}

The work here shows an important application of MOF materials in the healthcare sector. MOFs have not been studied previously for breath sensing and sleep apnea related health problems and we believe more attention is warranted in this direction. A HKUST$1-\mathrm{MoS}_{2}$ hybrid sensor has been prepared on a flexible and economical support that makes it a sustainable and user friendly breath sensor which is stable and responsive to various breath types. The current work will open up a new area for MOF applications and more MOF materials on various flexible supports will be studied in future to design and test breath sensors under different humidity conditions.

\section{Experimental}

\section{Synthesis of HKUST-1}

$\mathrm{Cu}\left(\mathrm{NO}_{3}\right)_{2} \cdot 3 \mathrm{H}_{2} \mathrm{O}(1.4 \mathrm{mmol})$ and 1,3,5-benzene tricarboxylic acid $(0.8 \mathrm{mmol})$ were dissolved in $10 \mathrm{ml}$ of water, ethanol and DMF mixture in the ratio $2: 1: 1$. The solution was sonicated for about 10 minutes until the reagents were dissolved completely. The vial was then placed in an oven at $373 \mathrm{~K}$. The vial was removed from the oven after $12 \mathrm{~h}$ and cooled to room temperature. The blue crystals thus obtained were washed thoroughly with DMF and ethanol. The resulting product was then dried at $333 \mathrm{~K}$ for further characterization.

\section{$\mathrm{MOF}-\mathrm{MoS}_{2}$ device preparation}

$\mathrm{MoS}_{2}$ is directly grown by a hydrothermal process. For dropcasting MOF on $\mathrm{MoS}_{2}, 1 \mathrm{wt} \%$ of MOF solution was dispersed uniformly in ethanol and $100 \mu \mathrm{l}$ of this solution was then dropcast on to the $\mathrm{MoS}_{2}$ coated flexible support. 


\section{Characterization}

Thermogravimetric analysis. The thermal stability of the assynthesized sample was analysed by TGA. TGA was recorded from $30{ }^{\circ} \mathrm{C}$ to $800{ }^{\circ} \mathrm{C}$ under a $\mathrm{N}_{2}$ atmosphere using a Shimadzu DTG-60 instrument. The heating rate was maintained at $10{ }^{\circ} \mathrm{C}$ $\min ^{-1}$. The sample showed good thermal stability up to $300{ }^{\circ} \mathrm{C}$. The initial weight loss up to $150{ }^{\circ} \mathrm{C}$ can be attributed to the solvent loss, whereas ligand decomposition takes place beyond $300{ }^{\circ} \mathrm{C}$.

Powder X-ray diffraction. The crystallinity and phase purity of the as-synthesized crystals were determined from the powder X-ray diffraction (PXRD) pattern. The XRPD pattern was recorded using a Rigaku Ultima-IV diffractometer supplied with $\mathrm{Cu} \mathrm{K} \alpha$ radiation $(40 \mathrm{kV}, 40 \mathrm{~mA})$ as the source in the $2 \theta$ range of $5^{\circ}-40^{\circ}$ with a step size of $2^{\circ} \min ^{-1}$. The phase purity of the experimental PXRD pattern was confirmed by comparing it with the simulated XRPD pattern.

Nitrogen adsorption. $\mathrm{N}_{2}$ sorption isotherms were recorded for the activated crystals and ground sample of HKUST-1 using a Microtrac Bel - BEL SORP mini II model surface area analyzer. The BET surface area, pore size, and pore volume of the samples were determined from the $\mathrm{N}_{2}$ sorption isotherms. The obtained values were in close proximity with the reported values.

Scanning electron microscopy. SEM images were obtained using an FEI Apreo LoVac instrument. The SEM images showed octahedral crystals with sharp edges in the range of 10-30 $\mu \mathrm{m}$. The SEM images of the as-synthesized HKUST-1 MOF, $\mathrm{MoS}_{2}$ on the paper support and HKUST-1 MOF dropcast on the $\mathrm{MoS}_{2}$ coated paper support were collected for surface analysis. X-ray photoelectron spectroscopy (XPS) experiments were performed to identify the elemental composition and the oxidation state of the elements present in the sample.

X-ray photoelectron spectroscopy. XPS was performed using a Thermo Scientific K- $\alpha$ instrument. The source used was an $\mathrm{Al}$ $\mathrm{K}-\alpha$ source [X-ray source $1486.8 \mathrm{eV}$ ].

\section{Conflicts of interest}

There are no conflicts to declare.

\section{Acknowledgements}

HA thanks DST-SERB for funding (grant sanction order number SRG/2019/000952) and TL thanks BITS-Pilani, Hyderabad, for the institute fellowship.

\section{Notes and references}

1 H. Furukawa, K. E. Cordova, M. O'Keeffe and O. M. Yaghi, Science, 2013, 341, 1230444.

2 Z. X. Kang, L. L. Fan and D. F. Sun, J. Mater. Chem. A, 2017, 5, 10073-10091.

3 P. Lama, H. Aggarwal, C. X. Bezuidenhout and L. J. Barbour, Angew. Chem., Int. Ed., 2016, 55, 13271-13275.
4 K. Adil, Y. Belmabkhout, R. S. Pillai, A. Cadiau, P. M. Bhatt, A. H. Assen, G. Maurin and M. Eddaoudi, Chem. Soc. Rev., 2017, 46, 3402-3430.

5 P. Horcajada, R. Gref, T. Baati, P. K. Allan, G. Maurin, P. Couvreur, G. Ferey, R. E. Morris and C. Serre, Chem. Rev., 2012, 112, 1232-1268; P. Garcia-Garcia, M. Muller and A. Corma, Chem. Sci., 2014, 5, 2979-3007.

6 H. Li, M. Eddaoudi, M. O'Keeffe and O. M. Yaghi, Nature, 1999, 402, 276-279.

7 M. Bosch, S. Yuan, W. Rutledge and H. C. Zhou, Acc. Chem. Res., 2017, 50, 857-865.

8 P. Samanta, A. V. Desai, S. Let and S. K. Ghosh, ACS Sustainable Chem. Eng., 2019, 7, 7456-7478.

9 D. J. Wales, J. Grand, V. P. Ting, R. D. Burke, K. J. Edler, C. R. Bowen, S. Mintova and A. D. Burrows, Chem. Soc. Rev., 2015, 44, 4290-4321.

10 A. Mallick, A. M. El-Zohry, O. Shekhah, J. Yin, J. T. Jia, H. Aggarwal, A. H. Emwas, O. F. Mohammed and M. Eddaoudi, J. Am. Chem. Soc., 2019, 141, 7245-7249.

11 Z. Hu, B. J. Deibert and J. Li, Chem. Soc. Rev., 2014, 43, 5815-5840; R. Goswami, S. C. Mandal, N. Seal, B. Pathak and S. Neogi, J. Mater. Chem. A, 2019, 7, 19471-19484.

12 N. R. Jalal, T. Madrakian, A. Afkhami and A. Ghoorchian, ACS Appl. Mater. Interfaces, 2020, 12, 4859-4869.

13 H. Yamagiwa, S. Sato, T. Fukawa, T. Ikehara, R. Maeda, T. Mihara and M. Kimura, Sci. Rep., 2015, 4, 6247.

14 L. E. Kreno, K. Leong, O. K. Farha, M. Allendorf, R. P. Van Duyne and J. T. Hupp, Chem. Rev., 2012, 112, 1105-1125.

15 S. Khatua and P. Biswas, ACS Appl. Mater. Interfaces, 2020, 12, 22335-22346.

16 S. Achmann, G. Hagen, J. Kita, I. M. Malkowsky, C. Kiener and R. Moos, Sensors, 2009, 9, 1574-1589.

17 C. H. Chuang and C. W. Kung, Electroanalysis, 2020, 32, 1885-1895.

18 N. Hanikel, M. S. Prévot and O. M. Yaghi, Nat. Nanotechnol., 2020, 15, 348-355.

19 H. Kim, S. Yang, S. R. Rao, S. Narayanan, E. A. Kapustin, H. Furukawa, A. S. Umans, O. M. Yaghi and E. N. Wang, Science, 2017, 356, 430-434.

20 H. Furukawa, F. Gándara, Y. B. Zhang, J. Jiang, W. L. Queen, M. R. Hudson and O. M. Yaghi, J. Am. Chem. Soc., 2014, 136, 4369-4381.

21 K. N. Chappanda, O. Shekhah, O. Yassine, S. P. Patole, M. Eddaoudi and K. N. Salama, Sens. Actuators, B, 2018, 257, 609-619.

22 A. Weiss, N. Reimer, N. Stock, M. Tiemann and T. Wagner, Microporous Mesoporous Mater., 2016, 220, 39-43.

23 S. M. Towsif Abtab, D. Alezi, P. M. Bhatt, A. Shkurenko, Y. Belmabkhout, H. Aggarwal, L. J. Weseliński, N. Alsadun, U. Samin, M. N. Hedhili and M. Eddaoudi, Chem., 2018, 4, 94-105.

24 Y. Yang, X. Yang, Y. Tan and Q. Yuan, Nano Res., 2017, 10, 1560-1583.

25 V. C. De Cock, M. Abouda, S. Leu, D. Oudiette, E. Roze, M. Vidailhet, T. Similowski and I. Arnulf, Sleep Med., 2010, 1, 247-252. 
26 A. S. Shamsuzzaman, B. J. Gersh and V. K. Somers, JAMA, J. Am. Med. Assoc., 2003, 290, 1906-1914.

27 W. Lee, S. Nagubadi, M. H. Kryger and B. Mokhlesi, Expert Rev. Respir. Med., 2008, 2, 349-364.

28 T. Young, P. E. Peppard and S. Taheri, J. Appl. Physiol., 2005, 99, 1592-1599.

29 M. Shokoueinejad, C. Fernandez, E. Carroll, F. Wang, J. Levin, S. Rusk and M. Teodorescu, Physiol. Meas., 2017, 38, R204.

30 C. Li, V. M. Lubecke, O. Boric-Lubecke and J. Lin, IEEE Trans. Microw. Theroy Tech., 2013, 61, 2046-2060.

31 V. Selamneni and P. Sahatiya, IEEE Sens. J., 2019, 20, 3452-3459.

32 S. Kanaparthi, Electroanalysis, 2017, 29, 2680-2684.

33 J. Canivet, A. Fateeva, Y. Guo, B. Coasne and D. Farrusseng, Chem. Soc. Rev., 2014, 43, 5594-5617.

34 S. K. Bhardwaj, N. Bhardwaj, R. Kaur, J. Mehta, A. L. Sharma, K.-H. Kim and A. Deep, J. Mater. Chem. A, 2018, 6, 14992-15009.

35 K. T. Butler, C. H. Hendon and A. Walsh, J. Am. Chem. Soc., 2014, 136, 2703-2706.

36 Z. G. Gu, L. Heinke, C. Woll, T. Neumann, W. Wenzel, Q. Li, K. Fink, O. D. Gordan and D. R. T. Zahn, Appl. Phys. Lett., 2015, 107, 183301.

37 J. W. Jiang, Front. Phys., 2015, 10, 287-302.

38 B. Du, D. Yang, X. She, Y. Yuan, D. Mao, Y. Jiang and F. Lu, Sens. Actuators, B, 2017, 251, 180-184.

39 T. Li and G. Galli, J. Phys. Chem. C, 2007, 111, 16192-16196.
40 P. Chowdhury, C. Bikkina, D. Meister, F. Dreisbach and S. Gumma, Microporous Mesoporous Mater., 2009, 117, 406-413.

41 P. M. Schoenecker, C. G. Carson, H. Jasuja, C. J. J. Flemming and K. S. Walton, Ind. Eng. Chem. Res., 2012, 51, 6513-6519.

42 G. Ananya, N. Pranati and S. Ramaprabhu, Int. J. Hydrogen Energy, 2016, 41, 3974-3980.

43 H. Sun, O. A. Zelekew, X. Chen, Y. Guo, D. H. Kuo, Q. Lu and J. Lin, RSC Adv., 2019, 9, 31828-31839.

44 A. Gigot, M. Fontana, M. Serrapede, M. Castellino, S. Bianco, M. Armandi, B. Bonelli, C. F. Pirri, E. Tresso and P. Rivolo, ACS Appl. Mater. Interfaces, 2016, 8, 32842-32852.

45 J. M. Yun, Y. J. Noh, C. H. Lee, S. I. Na, S. Lee, S. M. Jo, H. I. Joh and D. Y. Kim, Small, 2014, 10, 2319-2324.

46 P. Küsgens, M. Rose, I. Senkovska, H. Fröde, A. Henschel, S. Siegle and S. Kaskel, Microporous Mesoporous Mater., 2009, 120, 325-330.

47 J. B. DeCoste, G. W. Peterson, B. J. Schindler, K. L. Killops, M. A. Browe and J. J. Mahle, J. Mater. Chem. A, 2013, 1, 11922-11932.

48 N. C. Jeong, B. Samanta, C. Y. Lee, O. K. Farha and J. T. Hupp, J. Am. Chem. Soc., 2012, 134, 51-54.

49 M. A. Russo, D. M. Santarelli and D. O'Rourke, Breathe, 2017, 13, 298-309.

50 T. Young, P. E. Peppard and D. J. Gottlieb, Am. J. Respir. Crit. Care Med., 2002, 165, 1217-1239. 